\title{
Action before certainty for Africa's European migrant birds
}

\author{
Juliet A. Vickery and William M. Adams
}

In 1974, Winstanley et al. asked 'Where have all the whitethroats gone?'. This followed the failure of this small migrant bird to recover from a $77 \%$ decline in the UK breeding population in 1968-1969, the suggested cause being drought-related mortality in the Sahel. Whitethroats have slowly recovered, but many other small, Afro-Palearctic migrant passerines continue to decline. Despite a wealth of research, the underlying causes remain elusive (Vickery et al., 2014).

Put simply, developing and implementing initiatives to stem population declines requires knowing whether they are driven by changes in breeding success or survival. For most migrant passerines we are struggling to provide this information-but why? Firstly, these small migrant passerines represent a broad suite of ecologically different species, including aerial foragers such as the swift and swallow, woodland birds such as the nightingale and pied flycatcher, and open country species such as the whinchat and yellow wagtail, suggesting the declines are unlikely to be driven by a single common factor. Secondly, these species have complex life cycles, traversing vast tracts of the globe and using multiple sites and habitats. Thirdly, outside the breeding season these species occur in low densities over huge areas of Sub-Saharan Africa, a challenging environment for which we have little understanding of the activities that influence land use and land-use change.

Research capitalizing on technological and scientific advances has, however, provided some insights into the decline of these small passerine migrant birds. Remotely sensed land-cover and meteorological data allow us to look beyond annual patterns of rainfall to timing, duration and intensity of greening and senescence of vegetation at fine-scale resolutions (Beresford et al., 2018). With the miniaturization of tracking devices we can follow more species throughout their annual cycle, identifying migration routes, staging and wintering areas and even the location of mortality of individuals (Tøttrup et al., 2011; Hewson et al., 2016). Field studies in non-breeding areas have documented habitat preferences and/or tree selection by individual species, such as the wood warbler, or in particular habitats such as

JULIET A. VICKery Royal Society for the Protection of Birds, Sandy, Bedfordshire, SG19 2DL, UK, and University of Cambridge, David Attenborough Building, Pembroke Street, Cambridge, CB2 3QZ, UK

E-mail juliet.vickery@rspb.org.uk

William M. Adams Department of Geography, University of Cambridge, Cambridge, UK the Sahel (Zwarts et al., 2015; Mallord et al., 2018). However, the small sample sizes of fieldwork and tracking studies, particularly in Africa, make it impossible to draw general conclusions about multiple, complex and interacting factors operating over several years and across vast areas.

A final, key issue is that although these Afro-Palearctic passerines migrate across multiple political boundaries, joining north and south, they are not a shared conservation priority. The decline of common widespread migrant birds lacks the political and/or public appeal of a globally threatened species such as Gurney's pitta (Shwe, 2020). Many of the countries where migrants stage and winter lack conservation capacity and such that exists is directed at threatened, endemic and/or iconic species. The lack of global attention to these migrant passerines and the lack of inclusion of African scientists in work relating to these species add to the challenges.

So far we have followed the approach of determining the problem before developing the solution. But is this really cost-effective for a system in which diagnosing the problem is such a challenge and-more importantly-can we afford to wait given the precipitous declines of species such as the ortolan bunting (Menz \& Arlettaz, 2012)? We need action before certainty for Africa's European migrant birds. Although it remains important to continue some diagnostic research, particularly tagging and tracking birds, resources need to be re-focused on trialling best guess solutions.

Doing what we can will mean different actions along the Afro-Palearctic flyway at different temporal and spatial scales, combined with monitoring and adaptive actions. On the breeding grounds it may mean looking at where migrants are faring well and replicating these habitats elsewhere. For example, the biology of many of these small passerines indicates they may benefit from retention or creation of patches of scrub and woodland as breeding habitat, and measures to boost insect populations through reduction in chemical use and/or habitat creation. In African staging and wintering grounds our knowledge indicates the most beneficial generic action for widespread migrant passerines is retaining and enhancing tree cover, specifically measures beyond traditional forest protection. There are a growing number of international approaches to retain or enhance tree cover in this region. The Bonn Challenge, for example, aims to restore 350 million ha of deforested and degraded land by 2030, and Trillion Trees aims to regrow, or save from loss, one trillion trees by 2050 . Nationally, the Great Green Wall is an African-led initiative 
to grow 8,0oo km of trees across the width of the continent, and a large proportion of the aid and development money entering this region is directed at initiatives around agriculture and forestry.

In tree-planting initiatives what is planted and where is the key determinant of benefits for people (Mwangi \& Swallow, 2008) as well as for birds, with $>60 \%$ of tree species in the Sahel rarely if ever used by migrant birds (Zwarts et al., 2015). These aid and development initiatives provide a natural experiment. Monitoring them for their biodiversity value could identify modifications that would benefit birds without affecting people, or even benefit both. Such assessments would require careful design, over large spatial and temporal scales, given the inherent difficulty of monitoring mobile non-breeding populations (Wotton et al., 2020). Grassroots initiatives could also be monitored and those successful replicated or scaled up. Empowering African conservationists to develop schemes is likely to provide more sustainable long-term solutions. The Birds, Bees and Butter initiative, for example, aims to improve productivity of native shea trees (Stout et al., 2018) and to benefit insects and birds, and has built in socio-economic and biodiversity assessments. In the Sahel the re-creation of traditional bocage areas of fields surrounded by hedges and woodland, to improve the sustainability of crop and livestock management, could provide valuable habitat for both resident and migrant birds. Throughout West Africa the Ecovillage Movement, in which communities work to integrate ecological, economic, social and cultural dimensions of sustainability, is also gaining momentum (Liftin, 2014).

Conservationists frequently call for the coordination of flyway-scale action, but coordination of what is inevitably local action is only worth investment if it adds value. Perhaps the greatest potential for this is through raising awareness within and between diverse communities that they share the same birds and that the future of people and birds alike is affected by environmental change. Migrant birds offer a unique opportunity to link disparate communities, and the conservation of this suite of birds could have wider benefits for people and wildlife from Europe to Africa. Creating communities that care throughout the Afro-Palearctic flyway will require conservation scientists to work far more closely with aid and development in Africa.

As Newton (2010) so vividly put it 'We are concerned here not with the conservation just of individual species but with a spectacular biological phenomenon that for centuries has elicited a sense of awe and wonder in human kind.' For this phenomenon to continue we need to recognize that the decline of widespread relatively common species carries a stronger warning about the health of our natural world than the decline of rare and threatened species, and to afford them a higher priority (Redford et al.,
2013). We need to accept that conservation action in Africa cannot be done on the cheap whilst investing millions in the integration of agriculture and biodiversity in Europe, and we need to have the courage to act without scientific certainty and be willing to adapt, modify or even cease actions in the light of new information.

Acknowledgements Many of these thoughts arose from a sciencepolicy workshop funded under the Cambridge Conservation grant CCI-05-18-003 and we thank all the participants and the funders.

\section{References}

Beresford, A.E., Sanderson, F.J., Donald, P.F., Burfield, I.J., Vickery, J.A. \& Buchanan, G.M. (2018) Phenology and climate change in Africa and the decline of Afro-Palearctic migratory bird populations. Remote Sensing in Ecology and Conservation, 5, 55-69.

Hewson, C.M., Thorup, K., Pearce-Higgins, J.W. \& Atkinson, P.A. (2016) Population decline is linked to migration route in the common cuckoo. Nature Communications, 7, 12296.

Liftin, K.T. (2014) Ecovillages: Lessons for Sustainable Community. John Wiley \& Sons, London, UK.

Mallord, J.W., Orsman, C.J., Roberts, J.T., Boafo, K., Skeen, R.Q., Sheehan, D.K. \& VickerY, J.A. (2018) Apparent resilience of a declining Afro-Palaearctic migrant to forest loss on the wintering grounds. Ibis, 160, 805-815.

Menz, M.H.M \& Arlettaz, R. (2012) The precipitous decline of the ortolan bunting Emberiza hortulana: time to build on scientific evidence to inform conservation management. Oryx, 46, 122-129.

Mwangi, E. \& Swallow, B. (2008) Prosopis juliflora invasion and rural livelihoods in the Lake Baringo Area of Kenya. Conservation and Society, 6, 130-140.

Newton, I. (2010) Bird Migration. Harper Collins, London, UK.

Redford, K.H., Berger, J \& ZACK, S. (2013) Abundance as a conservation value. Oryx $47,157-158$.

Shwe, N.M., Sukumal, N., Grindley, M. \& Savini, T. (2020) Is Gurney's pitta Hydrornis gurneyi on the brink of extinction? Oryx, 54, 16-22.

Stout, J.C., Nombre, I., de Bruijn, B., Delaney, A., Doke, D.A., GyıмAн, T. et al. (2018) Insect pollination improves yield of shea in the agroforestry parklands of West Africa. Journal of Pollination Ecology, 22, 11-20.

Tøttrup, A.P., Klaasen, R.H.G., Strandberg, R., Thorup, K., Kristensen, M.W., Jørgensen, P.S. et al. (2011) The annual cycle of a trans-equatorial Eurasian-African passerine migrant: different spatio-temporal strategies for autumn and spring migration. Proceedings of the Royal Society B Biological Sciences, 279, 1008-1016.

Vickery, J.A., Ewing, S.R., Smith, K.W., Pain, D.J., Bairlein, F., ŠKorpilová, J. \& Gregory, R.D. (2014) The decline of AfroPalearctic migrants and an assessment of potential causes. Ibis, 156, 1-22.

Winstanley, D., Spencer, R. \& Williams, K. (1974) Where have all the whitethroats gone? Bird Study, 21, 1-14.

Wotton, S.R., Eaton, M.A., Sheehan, D., Barasa Munyekenye, Burfield, I.J., Butchart, S.H.M. et al. (2020) Developing biodiversity indicators for African birds. Oryx, 54, 62-73.

Zwarts, L., Bijlsma, R.G., van der Kamp, J., Sikkema, M. \& Wymenga, E. (2015) Moreau's paradox reversed, or why insectivorous birds reach high densities in savanna trees. Ardea, 103, 123-145. 